\title{
Assay for Rapid Screening of Phytochemicals as Antimicrobial Agents
}

\author{
${ }^{1}$ Ghosh Saurav, ${ }^{2}$ Indranil Mukherjee, ${ }^{3}$ Ashoke Ranjan Thakur and ${ }^{1}$ Shaon Ray Chaudhuri \\ ${ }^{1}$ Department of Biotechnology, School of Biotechnology and Biological Sciences, \\ West Bengal University of Technology, BF-142, Sector-1, Salt Lake, Kolkata-700064, West Bengal, India \\ ${ }^{2}$ Department of Natural Sciences, School of Management and Sciences, \\ West Bengal University of Technology, BF-142, Sector-1, Salt Lake, Kolkata-700064, India \\ ${ }^{3}$ Techno India University, Vice Chancellor's Unit, EM4/1, Sector V, Salt Lake, Kolkata-700091, India
}

Received 2012-11-21, Revised 2013-01-07; Accepted 2013-01-22

\begin{abstract}
The present study aims to develop a rapid method for antibiotic sensitivity detection and screening of natural products for antimicrobial activity. The dimension of WBC in blood film was found to get altered when seeded with bacteria and monitored under light microscope. The shrinkage was prevented in response to antibiotic treatment and validated using statistical analysis (two sample one tailed $\mathrm{Z}$ test). Thus here is a prompt $(4 \mathrm{~h})$ assay system for detection of blood infection, antibiotic sensitivity detection as well as natural antimicrobial candidate molecule screening using identical procedure. The antimicrobial activity of ethanolic leaf extract of Mentha spicata against multidrug resistant Pseudomonas auregenosa from clinical origin was screened using both conventional disc diffusion method and the rapid shrinkage method. Both the methods showed equal efficiency with the later being much faster $(4 \mathrm{~h})$ than the conventional method $(72 \mathrm{~h})$.
\end{abstract}

Keywords: Blood Infection, Bacterial Contamination, WBC, Phytochemical, Antimicrobial Screening

\section{INTRODUCTION}

Multidrug resistance is increasing rapidly, so newer drugs are essential for treating such pathogens. A system for screening the new candidate formulations from natural origin is a must. The medicinal plants are those which contain substances that can be used for therapeutic purposes (Sofowora, 1982). WHO also reported the use of traditional medicines by about three quarter of the world population (Rao et al., 2004) India has a major collection of medicinal plants and traditional knowledge regarding its use which is put into practice by about $70 \%$ of its rural population (http://www.aayisrecipes.com/2009/04/01/brahmi/). In traditional medicine, the plant parts are simply eaten raw, cooked or infused in water or native wine or even prepared as food apart. In case of orthodox medicine the plant parts are often subjected to chemical processes for extraction of the crude preparations of the active ingredient before the purified compound is available for consumption (Conway, 1973). The antibacterial properties of many plants used in traditional medicine are now being studied in light of the rapid development of antibiotic resistant species. Most of these plants are rich in secondary metabolites, such as tannins, terpenoids, glycosides, alkaloids and flavonoids rich in antimicrobial properties (Padmini et al., 2010; Neelima et al., 2011). With the discovery of penicillin in 1928, the tide in the war between humans and pathogenic bacteria species was thought to turn in favour of the humans. But the application of Penicillin in clinical medicine by Florey, Chain and Colleagues in 1941 was soon followed by the introduction of antibiotic-resistant Staphylococcus aureus (Charles and Grayson, 2004). Antibiotic use in the agri-food industry-in cattle, poultry, fish farming, where it is used as growth promoters, estimated to be Corresponding Author: Ray Chaudhuri, S., Department of Biotechnology, West Bengal University of Technology, BF-142, Sector-1, Salt Lake, Kolkata-700064, West Bengal, India 
1000-fold greater in terms of tonnage compared with their use in humans. With the development of panresistant bacteria and spread of the 1., resistance to antimicrobials, bacteria are fast catching up (Hawkey and Jones, 2009). WHO has stated that antimicrobial resistance is one of the greatest threats to human health with 25000 deaths from infections caused by multidrug resistant bacteria in the European Union? With the isolation of antibiotic resistant $E$. coli containing the panresistant gene NDM1 (New Delhi metallo- $\beta$-lactamase) in India, completely resistant bacteria are no longer just hospital acquired but are spilling over into the community (Charan et al., 2012). The standard method of doing the same is usually testing the potency of the drugs against the bacteria on a Muller Hinton Agar Plate. But earlier studies have illustrated a unique system of detecting contamination in blood within an invitro system in $4 \mathrm{~h}$ (Zahniser et al., 1983; Prokocimer and Potasman, 2008). The aim of this study is to promptly check the antimicrobial efficiency of phytochemical extract against microbes within an invitro mammalian system (blood) instead of solid culture media plates.

\section{MATERIALS AND METHODS}

\subsection{Selection of Participants}

The participants (mostly the 1st and corresponding author) were selected depending on the fact that they were not under any medication during the course of this study.

\subsection{Blood Bacterial Interaction}

Blood sample with anticoagulant was seeded with 1822 cells of known $P$. auregenosa from clinical origin for which the antibiotic sensitivity was tested. From the earlier literature, the particular $P$. auregenosa strain was reported as resistant to all commercially available antibiotics (Nandy et al., 2007). Ethanol extract of Mentha spicata which shows sensitivity towards this strain of P.auregenosa in MHA plates was used for this study. Separate parallel experiments were setup using non seeded blood (control), seeded blood with natural plant extract (lyophilized powder of the ethanolic Mentha spicata extract suspended in $1 \times$ PBS; $\mathrm{pH} 7.2$ ). The whole set was incubated at $37^{\circ} \mathrm{C}$ water bath for $3 \mathrm{~h}$. After $3 \mathrm{~h}$ incubation, blood film was drawn on cleaned glass slides for each of the three sets. It was then dipped into fixative (3\% acetic acid in 95\% methanol) for $1 \mathrm{~min}$ and washed with distilled water. After that Leishman stain (HiMedia) was flooded onto the slides and incubated for $20 \mathrm{sec}$. Then $2 \mathrm{~mL}$ of $6.8 \mathrm{pH}$ buffers (50.5\% of $0.2 \mathrm{M} \mathrm{NaH} \mathrm{PO}_{4}+49.5 \%$ of $0.2 \mathrm{M} \mathrm{Na} \mathrm{NPO}_{4}$ ) was added and stirred for $7 \mathrm{~min}$ followed by washing with water. $2 \mathrm{ml}$ of $6.8 \mathrm{pH}$ buffer (solution A-0.2 $\mathrm{M} \mathrm{NaH}_{2} \mathrm{PO}_{4}+$ solution $\mathrm{B}-0.2 \mathrm{M} \mathrm{Na}_{2} \mathrm{HPO}_{4}$ ) was added and kept for 2 min before being washed with water. The nucleus of the white blood cells took a dark purple stain, when observed under $100 \times$ of axiostar plus fluorescence microscope by Zeiss. The entire process of monitoring WBC dimension was carried out for each set. In order to minimize the error while measuring, the images were projected on a screen with the help of a LCD projector and the dimension of each cell was taken by plotting three straight lines passing through the centre. The last step could be replaced with measuring the dimension of WBC using digital software associated with microscopic visualization facility.

\subsection{Statistical Analysis}

Since the sample size was 30 , two different samples were involved and a one-way inequality was under consideration, a two- sample one-tailed $\mathrm{Z}$ test was used for statistical analysis in both the cases.

For statistical analysis the dimension of control cells would be denoted by $\mu_{\mathrm{n}}$, bacteria + extract treated cells by $\mu_{\mathrm{a}+\mathrm{b}}$ and that of just bacteria seeded cells by $\mu_{\mathrm{b}}$ :

- Null Hypothesis $\left(\mathrm{H}_{0}\right): \mu_{\mathrm{b}}=\mu_{\mathrm{n}}$ and Alternative hypothesis $\left(\mathrm{H}_{1}\right): \mu_{\mathrm{b}}<\mu_{\mathrm{n}}$

- Sample size was $\mathrm{n}_{\mathrm{b}}=\mathrm{n}_{\mathrm{c}}=30$, Level of significance $\alpha$ $=5 \%$

The $\mathrm{Z}$ statistic was computed as follows Equation 1:

$$
\mathrm{Z}=\frac{\left(\mathrm{x}_{\mathrm{b}}-\mathrm{x}_{\mathrm{n}}\right)-\left(\mu \mathrm{b}-\mu_{\mathrm{n}}\right)_{\mathrm{H}_{0}}}{\sqrt{\frac{\left(\mathrm{s}_{\mathrm{b}}\right)^{2}}{\mathrm{n}_{\mathrm{b}}}+\frac{\mathrm{s}_{\mathrm{n}}^{2}}{\mathrm{n}_{\mathrm{c}}}}}
$$

Similarly a two-sample one-tailed $\mathrm{Z}$ test was conducted for validating the inhibition of WBC shrinkage in presence of plant extracts. In this case, the dimension of control cells was denoted by $\mu_{\mathrm{n}}$, and that of the bacteria + antimicrobial agent treated cells by $\mu_{\mathrm{a}+\mathrm{b}}$ :

- Null Hypothesis $\left(\mathrm{H}_{0}\right): \mu_{\mathrm{a}+\mathrm{b}}=\mu_{\mathrm{n}}$ and Alternative hypothesis $\left(\mathrm{H}_{1}\right): \mu_{\mathrm{a}+\mathrm{b}}<\mu_{\mathrm{n}}$

- Sample size was $n_{b}=n_{c}=30$, Level of significance $\alpha=5 \%$

The $\mathrm{Z}$ statistic was given by:

$$
\mathrm{Z}=\frac{\left(\mathrm{x}_{\mathrm{a}+\mathrm{b}}-\mathrm{x}_{\mathrm{n}}\right)-\left(\mu \mathrm{a}+\mathrm{b}-\mu_{\mathrm{n}}\right)_{\mathrm{H}_{0}}}{\sqrt{\frac{(\mathrm{Sa}+\mathrm{b}\lrcorner^{2}}{\mathrm{n}_{\mathrm{a}+\mathrm{b}}}+\frac{\mathrm{s}_{\mathrm{n}}^{2}}{\mathrm{n}_{\mathrm{c}}}}}
$$




\section{RESULTS}

The bacteria cause shrinkage of the WBC membrane during infection while the antibiotic therapy prevents the shrinkage. In case of treated cells, the white blood cells showed shrinkage in size, thus leading to smaller dimension, while the control and the extract treated samples showed retention of cell shape, as depicted in (Fig. 1). The cell dimensions were measured for at least $30 \mathrm{WBC}$ for each set and their variation was found to be significant. This detection took less than $4 \mathrm{~h}$.

The average of these three measurements was calculated for all the 30 cells observed, which in turn was used to calculate the grand average for control (5.260 cm, standard deviation -0.616) and bacterial treated cells $(5.011 \mathrm{~cm}$, standard deviation -0.425$)$. In presence of plant extract the bacteria seeded blood cells showed a grand average of 5.133 with standard deviation-0.690.

By using the above formula (1) the value of $\mathrm{Z}$ was found to be -1.830 . On the other hand, the tabulated value of test statistic was 1.645 at the $5 \%$ level of significance. The computed value is more than the tabulated value, so there is sufficient statistical evidence to reject the Null hypothesis. Thus it can be concluded that the dimension of bacteria treated cells are less than that of normal cells.

The above exercise was also repeated and verified for 30 samples and with other bacteria like Klebsiella sp., S.aureus.
Similarly the two-sample one-tailed $\mathrm{Z}$ test conducted for validating the inhibition of WBC shrinkage in presence of plant extracts as per Equation 2 revealed the value of $Z$ to be -0.752 ; on the other hand the tabulated value of the test statistic was 1.645 at the $5 \%$ level of significance. Since the computed value is less than the tabulated value, there is enough statistical evidence to accept the Null hypothesis. Hence it can be concluded that the dimensions of normal and antibiotic treated cells are the same.

\section{DISCUSSION}

Natural medicine has become the new ray of hope against the MDR microbes. The case study confirms that the crude extract performs equally well in mammalian blood as on MHA media. Therefore the component of extract responsible for antimicrobial property has to be enlightened. On the other hand, as these traditional plants are consumed raw, therefore the impact of epiphytic micro flora on phytochemical must be elucidated.

The entire procedure can be replaced by using either a microscope with dimension measuring facility or even with a simple device more like the haemocytometer where the graduation would correspond to the dimension of the WBC. In case of contamination the cell size would shrink and the mere visualization under the microscope would be sufficient to assess the shrinkage.

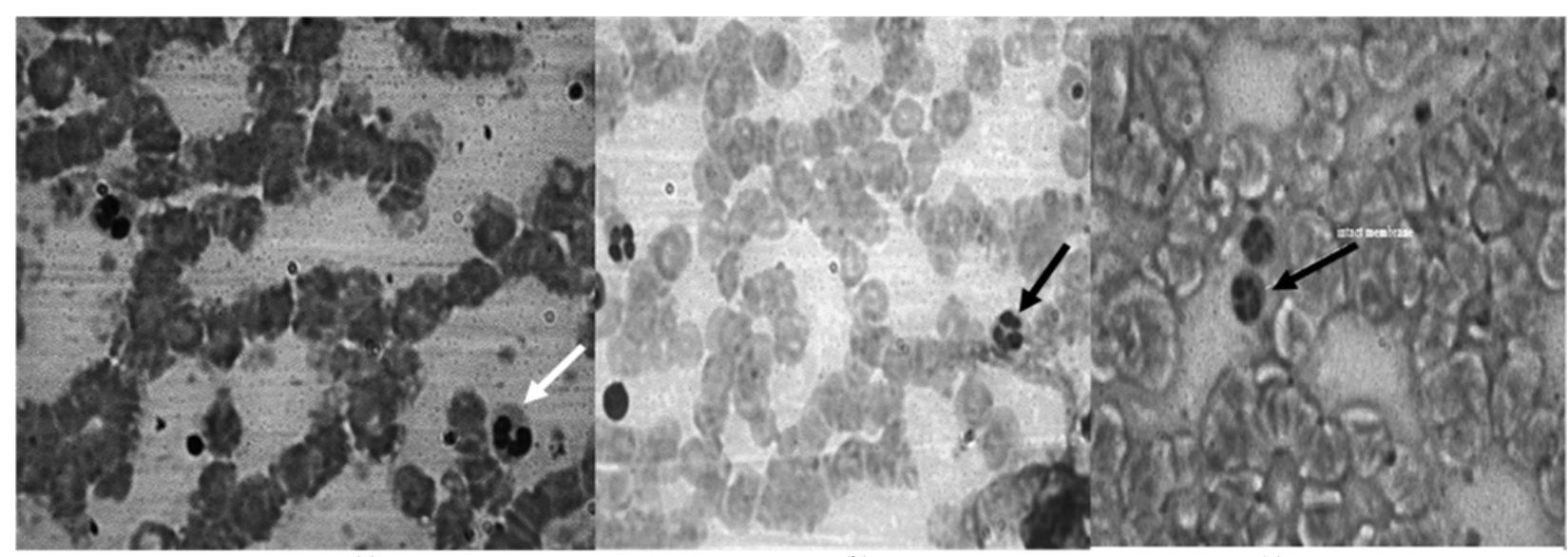

(a) (b) (c)

Fig. 1. Blood cells post Leishman staining in (a) control and (b) bacteria seeded and (c) bacteria seeded as well as plant extract treated, as observed under $100 \times$ of Axiostar Plus Fluorescence microscope from Zeiss 


\section{CONCLUSION}

Here we report a method for prompt detection of antibiotic sensitivity in blood within $4 \mathrm{~h}$ as opposed to the conventional $72 \mathrm{~h}$ used for the purpose. This method could also be used as a potential screening technique for natural pharmaceutical products. The above method can also be used in clinical laboratory and Diagnostic centres and laboratories.

\section{ACKNOWLEDGEMENT}

The researchers would like to thank the Department of Atomic Energy for functional assistance; West Bengal University of Technology for providing the laboratory as well as computational facility. The authors would like to thank the World Bank under the TEQIP program for providing the publication fee.

\section{REFERENCES}

Conway, D., 1973. The magic of Herbs. 1st Edn., Jonathan Cape, London. ISBN: 9780224008365, pp: 158.

Charles, P.G.P. and M.L. Grayson, 2004. The dearth of new antibiotic development: why we should be worried and what we can do about it. Med. J. Aus., 181: 549-553. PMID: 15540967

Charan, J., S. Mulla, S. Ryavanki and N. Kantharia, 2012. New Delhi Metallo-beta lactamase-1 containing enterobacteriaceae: Origin, diagnosis, treatment and public health concern. Pan. Afr. Med. J., 11: 22-29. PMID: 22514756

Hawkey, P.M. and A.M. Jones, 2009. The changing epidemiology of resistance. J. Antimicrob. Chemother., 64: i3-i10. DOI: 10.1093/jac/dkp256
Nandy, P., A.R. Thakur and S. RayChaudhuri, 2007. Characterization of bacterial strains isolated through microbial profiling of urine samples. Online J. Biol. Sci., 7: 44-51. DOI: 10.3844/ojbsci.2007.44.51

Neelima, N., N.G. Devidas, M. Sudhakar and V.J. Kiran, 2011. A preliminary phytochemical investigation on the leaves of Solanum xanthocarpum. IJRAP, 2: 845-850.

Padmini, E., A. Valarmathi and M. UshaRani, 2010. Comparative analysis of chemical composition and antibacterial activities of Mentha spicata and Camellia sinensis. Asian j. Exp. Biol. Sci., 1: 772- 781.

Prokocimer, M. and I. Potasman, 2008. The added value of peripheral blood cell morphology in the diagnosis and management of infectious diseases--part 1: basic concepts. Postgrad. Med. J., 84: 579-585. DOI: 10.1136/pgmj.2008.069609

Rao, K.V.K., S.A. Schwartz, H.K. Nair, R. Aalinkeel and S. Mahajan et al., 2004. Plant derived products as a source of cellular growth inhibitory phytochemicals on PC-3M, DU-145 and lncap prostate cancer cell lines. Current Sci., 87: 1585- 1588.

Sofowora, E.A., 1982. The State of Medicinal Plants' Research in Nigeria. UMI Books on Demand, Ann Arbor, ISBN-10: 0471103675, pp: 256.

Zahniser, D.J., J.F. Brenner, W.D. Selles and P.R. Daoust, 1983. Detecting infection-related changes in peripheral blood smears with image analysis techniques. Anal. Quant. Cytol., 5: 269-274. PMID: 6200019 